\title{
Antibiofilm Activity of Manuka Honey in Combination with Antibiotics
}

\author{
Michelle E. M. Campeau ${ }^{1,2}$ and Robin Patel ${ }^{1,3}$ \\ ${ }^{1}$ Division of Clinical Microbiology, Department of Laboratory Medicine and Pathology, Mayo Clinic, \\ 200 First Street S.W., Rochester, MN 55905, USA \\ ${ }^{2}$ Mayo High School, 1420 11th Avenue S.E., Rochester, MN 55904, USA \\ ${ }^{3}$ Division of Infectious Disease, Department of Medicine, Mayo Clinic, 200 First Streer S. W., Rochester, MN 55905, USA
}

Correspondence should be addressed to Robin Patel; patel.robin@mayo.edu

Received 17 November 2013; Revised 9 January 2014; Accepted 23 January 2014; Published 26 February 2014

Academic Editor: Mariagrazia Perilli

Copyright (C) 2014 M. E. M. Campeau and R. Patel. This is an open access article distributed under the Creative Commons Attribution License, which permits unrestricted use, distribution, and reproduction in any medium, provided the original work is properly cited.

\begin{abstract}
We assessed the in vitro activity of Manuka honey against biofilm bacteria in combination with antibiotics and visualized the effect of Manuka honey on bacterial biofilms using scanning electron microscopy. The fractional biofilm eradication concentration ( $\sum$ FBEC) index for vancomycin plus Manuka honey against $S$. aureus IDRL-4284 biofilms was 0.34, indicating a synergistic interaction. The $\sum$ FBEC index for gentamicin plus Manuka honey against $P$. aeruginosa PAO1 biofilms was $0.78-0.82$, indicating an additive interaction. Scanning electron microscopy of S. aureus IDRL-4284 and P. aeruginosa PAO1 biofilms exposed to Manuka honey and artificial honey containing the same sugar composition as Manuka honey showed that the former had more pronounced effects than the latter on both $S$. aureus and P. aeruginosa biofilms. Visualized effects included distorted cell morphologies for both bacteria and a decrease in P. aeruginosa extracellular matrix. In conclusion, Manuka honey has a synergistic interaction with vancomycin against $S$. aureus biofilms and an additive interaction with gentamicin against $P$. aeruginosa biofilms.
\end{abstract}

\section{Introduction}

Medicinal honeys are registered for topical application in several countries and are formulated in tubes, into ointments and gels, and made into wound dressings. A common medicinal honey is Manuka honey, from the Manuka bush (Leptospermum scoparium), indigenous to New Zealand and Australia. Manuka honey has a high sugar content (high osmolarity) and low $\mathrm{pH}$. Nonperoxide components are predominantly responsible for its antimicrobial activity $[1,2]$. It contains the antibacterial methylglyoxal $[3,4]$; although it also contains bee defensin-1, bee defensin-1 is modified by methylglyoxal, abrogating its antibacterial activity [5].

Manuka honey has in vitro activity against planktonic bacteria. It also possesses in vitro antibiofilm activity [6-13]. Given the topical uses of Manuka honey, its antibiofilm activity is clinically important, especially since most traditional antibiotics lack activity against biofilms. Preliminary studies demonstrate activity of Manuka honey against biofilms in humans $[6,14]$.
In medical practice, Manuka honey might be delivered in combination with traditional antibiotics, with both being administered topically or with Manuka honey being administered topically and the traditional antibiotic(s) being administered systemically. Therefore, it is useful to understand the interaction between Manuka honey and conventional antibiotics. Jenkins and Cooper reported a synergistic interaction between oxacillin and Manuka honey against a single strain of Staphylococcus aureus grown in the planktonic state [15]. They followed up their report by testing 15 antibiotics with Manuka honey against planktonic S. aureus and Pseudomonas aeruginosa using a variety of methods; five antibiotics exhibited improved activity with Manuka honey [16]. Aside from these studies, there has been little evaluation of the combination of Manuka honey with traditional antibiotics, and this strategy has not, to the best of our knowledge, been evaluated against bacterial biofilms.

Our goals were to evaluate the activity of Manuka honey with antibiotics against biofilm bacteria and to visualize 
effects of Manuka compared to artificial honey on biofilms using electron microscopy.

\section{Materials and Methods}

2.1. Bacterial Strains. S. aureus IDRL-4284 (a clinical isolate) and $P$. aeruginosa $\mathrm{PAO} 1$ were studied.

2.2. Manuka and Artificial Honey. Active Manuka Honey UMF 16+ (Manuka Honey USA LLC, Orlando, FL http:// www.manukahoneyusa.com) and artificial honey were studied. Artificial honey was prepared according to Cooper et al. by dissolving $3 \mathrm{~g}$ sucrose, $15 \mathrm{~g}$ maltose, $81 \mathrm{~g} \mathrm{D}$-fructose, and $67 \mathrm{~g} \mathrm{D}$-glucose in $34 \mathrm{~mL}$ sterile water [17] and irradiating the solution with $4 \mathrm{kGy}$ gamma irradiation. Manuka honey was used as purchased. For testing described below, honey was dissolved in cation-adjusted Mueller Hinton broth (CAMHB) and confirmed to be sterile by plating an aliquot onto a sheep blood agar plate which was subsequently incubated overnight at $37^{\circ} \mathrm{C}$.

\subsection{Treatment of Established Biofilms with Combinations} of Manuka Honey and Antibiotics. The effect of Manuka honey and vancomycin alone and in combination against S. aureus, or Manuka honey and gentamicin alone and in combination against $P$. aeruginosa, was assessed using a modification of a previously-described assay for treatment of established biofilms [18]. Vancomycin was chosen for study against $S$. aureus because it is commonly used for serious staphylococcal infections and has activity against most $S$. aureus isolates, regardless of methicillin susceptibility. Gentamicin, an aminoglycoside, was chosen for study against $P$. aeruginosa; aminoglycosides may be administered topically or systemically for the treatment of $P$. aeruginosa infection. Antibiotic solutions were prepared from stock solutions of $8 \mathrm{mg}$ of vancomycin or gentamicin in $4 \mathrm{~mL}$ of CAMHB; concentrations tested were $0,1,2.5,5,10,15,20,25,50,75$, 100 , and $500 \mu \mathrm{g} / \mathrm{mL}$. For S. aureus, concentrations of Manuka honey tested alone and in combination with vancomycin were $0,1,2,3,4,5,7.5$, and $10 \%$ (vol/vol) in CAMHB; for $P$. aeruginosa, concentrations of Manuka honey tested alone and in combination with gentamicin were $0,10,15,17.5$, $20,22.5,25$, and $30 \%$ (vol/vol) in CAMHB. Five colonies of each bacterium were placed in $10 \mathrm{~mL}$ of trypticase soy broth (TSB), vortexed, and incubated overnight at $37^{\circ} \mathrm{C}$. Then, they were adjusted to a turbidity of $1.0 \mathrm{McFarland}$, diluted 1:50 in TSB, and vortexed. $150 \mu \mathrm{L}$ aliquots of bacterial solution was placed into wells of a 96 -well microtiter well plate with a pegged lid and incubated overnight at $37^{\circ} \mathrm{C}$. The next day, the pegged lids were placed into plates containing $200 \mu \mathrm{L}$ Manuka honey and/or vancomycin or gentamicin in CAMHB and incubated overnight at $37^{\circ} \mathrm{C}$. The following day, pegged lids were placed in microtiter well plates containing sterile water for 30 seconds (to rinse off the honey and/or antibiotic) and then transferred to a microtiter well plate containing $200 \mu \mathrm{L}$ of CAMHB per well. The $\mathrm{OD}_{600}$ of the plate containing the honey and/or antibiotic was measured using a spectrophotometer, and the minimum inhibitory concentration (MIC) estimated as the lowest concentration of honey or antibiotic that resulted in an $\mathrm{OD}_{600}<0.2$ for $S$. aureus and $<0.4$ for $P$. aeruginosa (because of the higher concentrations of Manuka honey studied). The CAMHB plates were incubated overnight at $37^{\circ} \mathrm{C}$. The following day, the pegged lids were removed and the $\mathrm{OD}_{600}$ was measured using a spectrophotometer. The minimum biofilm eradication concentration (MBEC) was defined as the lowest concentration of honey or antibiotic to result in an $\mathrm{OD}_{600}<$ 0.200 .

The fractional biofilm eradication concentration (FBEC) of vancomycin or gentamicin in combination with Manuka honey was calculated as follows [19]:

$\frac{\text { MBEC of antibiotic in the presence of Manuka honey }}{\text { MBEC of antibiotic alone }}$

The FBEC of Manuka honey was calculated as follows:

MBEC of Manuka honey in the presence of antibiotic MBEC of Manuka honey

The two FBEC values were added to give the $\sum$ FBEC index. An $\sum$ FBEC index of $\leq 0.5$ indicates a synergistic effect, $>0.5$ to 1 indicates an additive effect, $>1$ to $<2$ indicates indifference, and $\geq 2$ indicates antagonism.

\subsection{Electron Microscopy of Biofilms Exposed to Manuka and} Artificial Honey. S. aureus and P. aeruginosa biofilms on Teflon discs were exposed to Manuka and artificial honey and imaged using scanning electron microscopy. For $P$. aeruginosa, Manuka honey concentrations of 15, 20, 25, and $30 \%$ and an artificial honey concentration of $50 \%(\mathrm{vol} / \mathrm{vol})$ in CAMHB were studied. For S. aureus, Manuka honey concentrations of $1.5,3,5,7.5$, and $10 \%$ and an artificial honey concentration of $50 \%(\mathrm{vol} / \mathrm{vol})$ in CAMHB were studied. The higher artificial honey concentrations were selected because prior experiments had shown artificial honey to have MBEC values $>35 \%$ for both $S$. aureus IDRL-4284 and P. aeruginosa PAO1, higher than the respective values for Manuka honey (data not shown). For each honey concentration studied, two discs were prepared, one for quantitative culture and another for electron microscopy. $12.5 \mathrm{~mm}$ diameter discs were cut from a $1 \mathrm{~mm}$ thick Teflon sheet using a punch biopsy instrument and hammer. After marking each with a black dot on one side for orientation purposes, they were autoclaved. Five colonies of each bacterium were placed in $45 \mathrm{~mL}$ of TSB, vortexed, and incubated overnight at $37^{\circ} \mathrm{C}$. After incubation, the solutions were adjusted to a turbidity of $1.0 \mathrm{McF}$ arland, diluted 1:50 in TSB, and vortexed. $1 \mathrm{~mL}$ aliquots of bacterial solution was placed into wells of a 24 -well flat bottomed microtiter plate. A sterile disc was placed into each well using tweezers, with the dot not showing. The plates were incubated overnight at $37^{\circ} \mathrm{C}$. The next day, after being dipped into sterile water, the discs were moved into a new 24 well plate containing honey solutions in CAMHB and incubated overnight at $37^{\circ} \mathrm{C}$. 


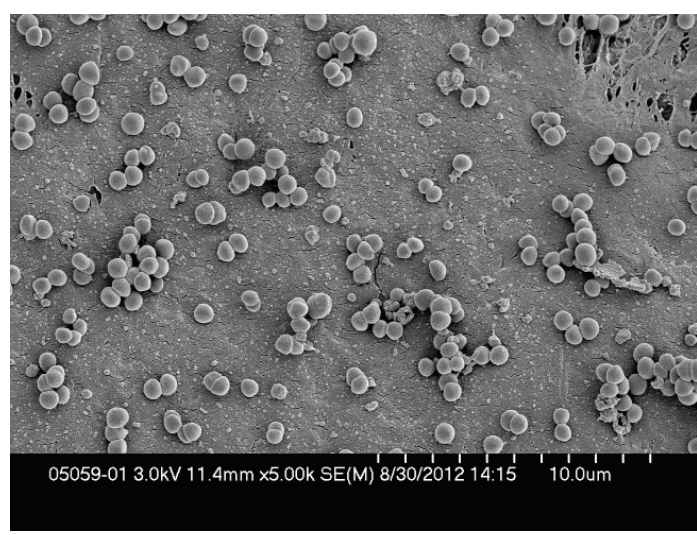

(a)

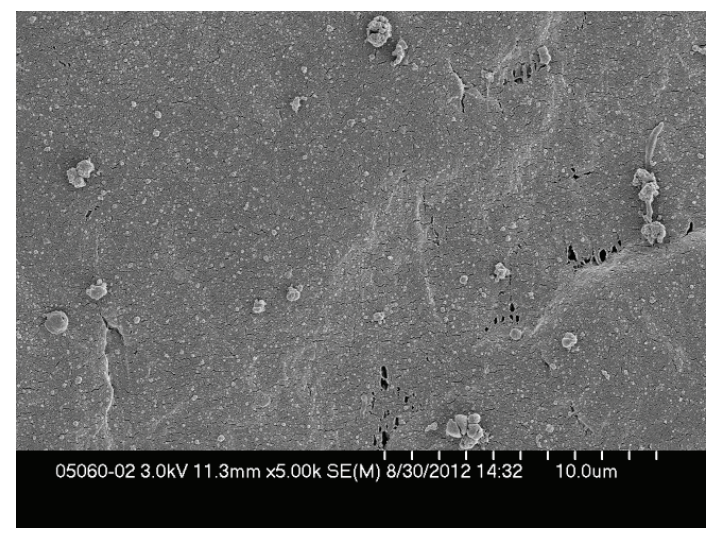

(b)

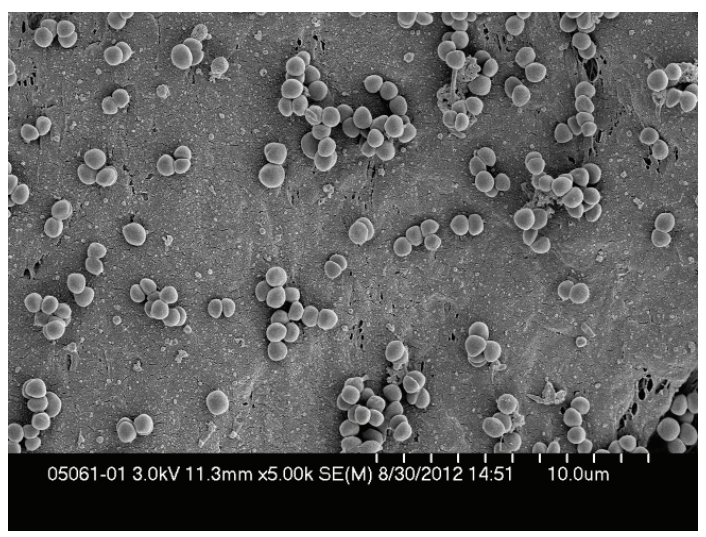

(c)

FiguRE 1: Scanning electron microscopy of S. aureus biofilms (scale bar, $1 \mu \mathrm{m}$ ) —(a) control; (b) 10\% Manuka honey; (c) 50\% artificial honey (representative images). The control biofilm appeared as numerous cells, all round spheres; those dividing retained their spherical shape. When treated with Manuka honey, the cell surfaces appeared rough and the cells were no longer spherical. The number of cells on the disc was dramatically decreased. The artificial honey appeared to have little effect on the cells; they appeared similar to the control cells in appearance and density.

The following day, the discs for electron microscopy were placed in $2.5 \mathrm{~mL}$ of Trump's solution ( $4 \%$ formaldehyde and $1 \%$ glutaraldehyde in a phosphate buffer, $\mathrm{pH} 7.3$ ) and refrigerated. The discs for quantitative culture were dipped in sterile water for 1 minute and placed in $2.5 \mathrm{~mL}$ TSB in a test tube, vortexed for 30 seconds, and bath sonicated for 5 minutes. Quantitative cultures were performed by plating five serial ten-fold dilutions in TSB onto sheep blood agar plates which were incubated overnight. The concentration of bacteria was calculated to determine which discs to examine using electron microscopy, and the respective discs in Trump's solution were submitted for scanning electron microscopy at the Mayo Clinic scanning electron microscopy core facility. Following critical-point drying and gold-palladium sputter coating, disks were imaged by cold-field emission scanning electron microscopy using a Hitachi S-4700 electron microscope (Hitachi Ltd., Tokyo, Japan).

\section{Results and Discussion}

3.1. Treatment of Established Biofilms with Combinations of Manuka Honey and Antibiotics. The MIC and the MBEC of Manuka honey against S. aureus IDRL-4284 were 2 and 3\%, respectively; the MIC and the MBEC of vancomycin were $\leq 1$ and $100 \mu \mathrm{g} / \mathrm{mL}$, respectively. The MIC and the MBEC of Manuka honey against $P$. aeruginosa PAO1 were 20 and 30\%, respectively; the MIC and the MBEC of gentamicin were 10 and $500 \mu \mathrm{g} / \mathrm{mL}$, respectively. Similar to our findings, Cooper et al. used an agar dilution method to show that the MIC of Manuka honey against S. aureus was 3\% [17], a finding Jenkins et al. recently showed extends to vancomycin-intermediate $S$. aureus [20]. Maddocks et al., however, reported higher MIC values, ranging from 6 to $20 \%$ using a broth microdilution method and four S. aureus isolates [13]. Cooper et al. used an agar dilution method to show that the mean MIC of Manuka honey against $P$. aeruginosa was 8\% [17], and Mullai and Menon reported a Manuka honey MIC of $10 \%$ against $P$. aeruginosa ATCC 27853 [21]; these values are slightly lower than found herein, possibly due to strain or methodology differences. Using a broth microdilution method, Maddocks et al. recently reported Manuka honey MIC values of 10 and $30 \%$ for two strains of $P$. aeruginosa, supporting straindependent variability [13]. There have been limited studies evaluating the effect of Manuka honey on $S$. aureus and $P$. aeruginosa biofilms. Alandejani et al. studied S. aureus and $P$. aeruginosa biofilms but only evaluated 50\% Manuka (and 


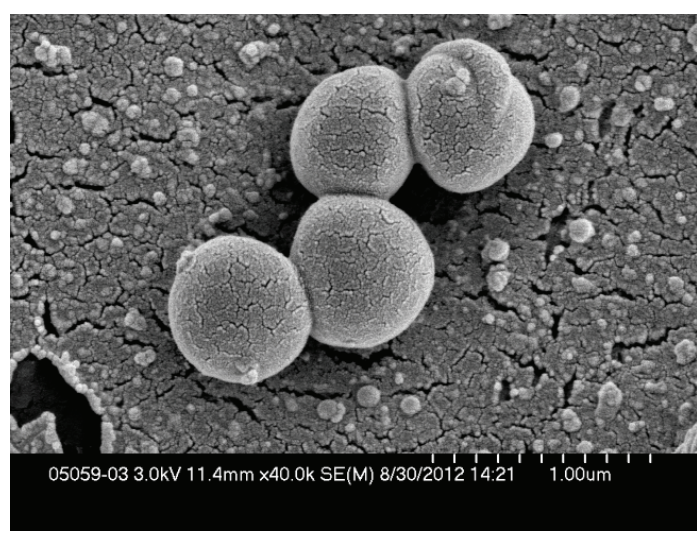

(a)

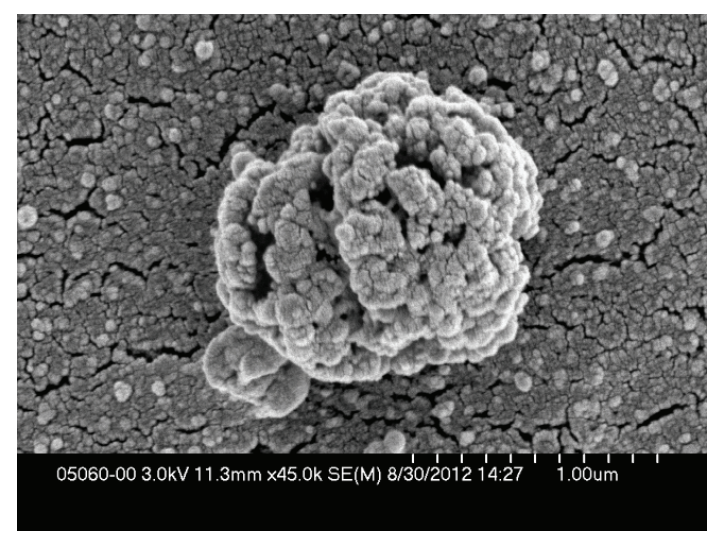

(b)

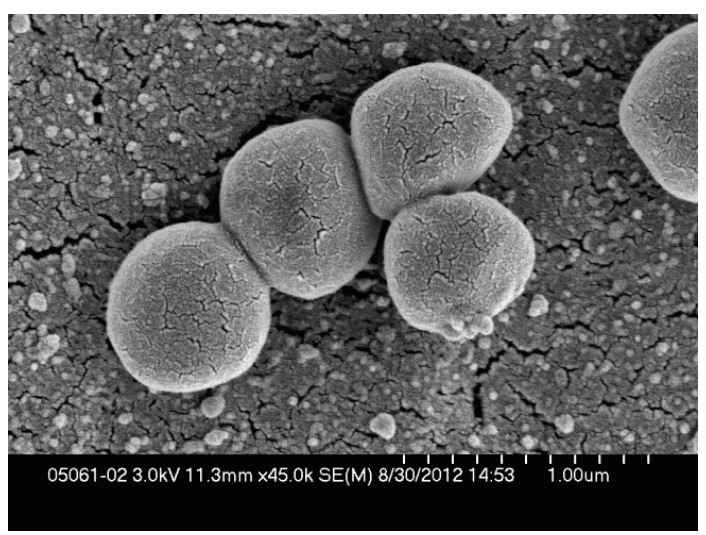

(c)

Figure 2: Scanning electron microscopy of S. aureus biofilms (scale bar, $0.1 \mu \mathrm{m}$ )—(a) control; (b) 10\% Manuka honey; (c) $50 \%$ artificial honey (representative images). In these close-up images, the differences seen in Figure 1 are emphasized. The Manuka honey-exposed cell had many holes and crevices in its surface, whereas the control cells and those exposed to artificial honey had a smooth exterior. The Manuka honey-exposed cells also appeared larger than the control or artificial honey-exposed cells.

Sidr) honey [7]. They reported that 50\% Sidr and Manuka honey killed 68 and $73 \%$, respectively, of the biofilms of 22 S. aureus strains tested and 91 and $91 \%$, respectively, of $11 P$. aeruginosa strains tested. We studied lower and likely more clinically relevant concentrations of Manuka honey. Majtan et al. have recently shown that methylglyoxal accounts for antibiofilm activity of Manuka honey [12].

We showed that subinhibitory Manuka honey concentrations increased vancomycin's activity against $S$. aureus biofilms and had an additive effect with gentamicin against P. aeruginosa biofilms (Table 1). Specifically, the fractional biofilm eradication concentration ( $\sum$ FBEC) index for the combination of vancomycin and Manuka honey against $S$. aureus biofilms was 0.34 , indicating a synergistic interaction. The $\sum$ FBEC index for the combination of gentamicin and Manuka honey against $P$. aeruginosa biofilms was $0.78-0.82$, indicating an additive interaction.

Although it has been suggested that Manuka honey may improve the activity of conventional antibiotics against planktonic bacteria $[15,16,22]$, as far as we know, no one has previously reported the antibiofilm activity of Manuka honey in combination with antibiotics. This is clinically relevant because medicinal honey is used topically in an environment where biofilms play a role, and conventional antibiotics may also be topically or systemically administered in cases of biofilm-associated infections managed with topical Manuka honey. It is possible that by combining Manuka honey and traditional antibiotics, emergence and spread of traditional antibiotic resistance may be impeded. Since traditional antibiotics and Manuka honey have different modes of action [23], one would be unlikely to select for cross-resistance to the other. Reassuringly, Cooper et al. have shown that the risk of emergence of resistance to Manuka honey itself is low [24].

3.2. Electron Microscopy of Biofilms Exposed to Manuka and Artificial Honey. Teflon discs with S. aureus biofilm exposed to 0 or $10 \%$ Manuka honey, or $50 \%$ artificial honey, which yielded 7.6, 7.2, and $7.4 \log _{10}$ colony forming units (cfu)/disc, respectively, and discs with $P$. aeruginosa biofilm exposed to 0 or $20 \%$ Manuka honey, or $50 \%$ artificial honey, which yielded $>7.6,3.8$ and $5.4 \log _{10} \mathrm{cfu} / \mathrm{disc}$, respectively, were subjected to scanning electron microscopy.

Images of $S$. aureus biofilms are shown in Figures 1 and 2. Manuka honey-exposed cells had roughened outer surfaces, were slightly enlarged, and had numerous surface 


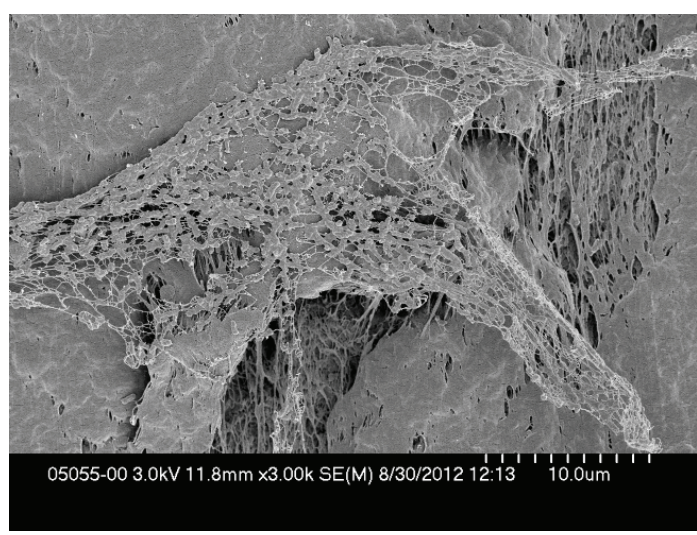

(a)

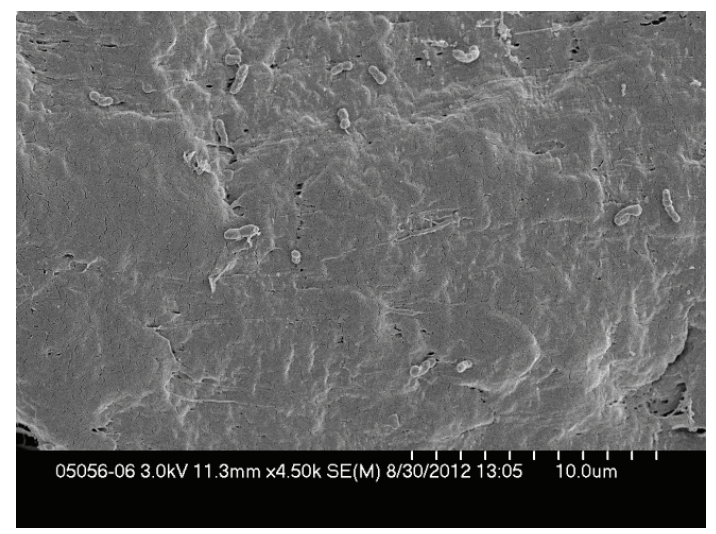

(b)

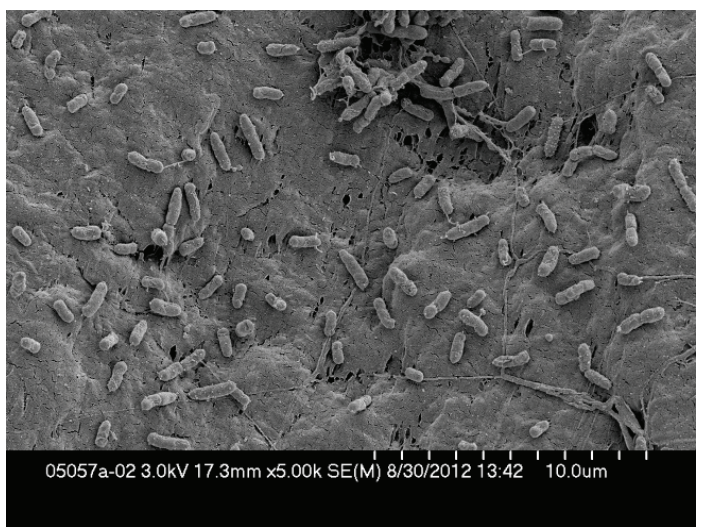

(c)

FIGURE 3: Scanning electron microscopy of P. aeruginosa biofilms (scale bar, $1 \mu \mathrm{m}$ )—(a) control; (b) 20\% Manuka honey; (c) $50 \%$ artificial honey (representative images). The control image showed hundreds of bacterial cells connected by a substantial amount of extracellular matrix which appeared stringy and covered most of the cells. The Manuka honey-exposed bacterial cells, in contrast, were spread apart with little apparent matrix. The cells appeared curved and distorted, and the cell density was markedly decreased. The artificial honey-exposed cells had a few connecting strands, but were mainly separate from one another. They less densely covered the disc than the control cells but more densely covered the disc than did the Manuka honey-exposed cells.

TABLE 1: $\sum$ FBEC indices.

\begin{tabular}{|c|c|c|c|c|c|}
\hline & \multicolumn{2}{|c|}{ MBEC of antibiotic } & \multicolumn{2}{|c|}{ MBEC of Manuka honey } & \multirow{2}{*}{$\sum$ FBEC index } \\
\hline & Alone & With Manuka honey & Alone & With antibiotic & \\
\hline \multirow[t]{2}{*}{$\begin{array}{l}\text { P. aeruginosa PAO1 } \\
\text { (gentamicin) }\end{array}$} & $500 \mu \mathrm{g} / \mathrm{mL}$ & $\begin{array}{c}100 \mu \mathrm{g} / \mathrm{mL} \text { with } \\
\text { 17.5\% Manuka honey }\end{array}$ & $30 \%$ & $\begin{array}{l}17.5 \% \text { with } \\
100 \mu \mathrm{g} / \mathrm{mL} \\
\text { gentamicin }\end{array}$ & 0.78 \\
\hline & & $\begin{array}{c}75 \mu \mathrm{g} / \mathrm{mL} \text { with } 20 \% \\
\text { Manuka honey }\end{array}$ & & $\begin{array}{c}20 \% \text { with } 75 \mu \mathrm{g} / \mathrm{mL} \\
\text { gentamicin }\end{array}$ & 0.82 \\
\hline $\begin{array}{l}\text { S. aureus } \\
\text { IDRL-4284 } \\
\text { (vancomycin) }\end{array}$ & $100 \mu \mathrm{g} / \mathrm{mL}$ & $\begin{array}{l}1 \mu \mathrm{g} / \mathrm{mL} \text { with } 1 \% \\
\text { Manuka honey }\end{array}$ & $3 \%$ & $\begin{array}{l}1 \% \text { with } 1 \mu \mathrm{g} / \mathrm{mL} \\
\text { vancomycin }\end{array}$ & 0.34 \\
\hline
\end{tabular}

holes and crevices. There was a noticeable difference in cell density compared to control biofilms, mirroring results of quantitative culture. The artificial honey-exposed cells had a similar overall appearance to control cells.

Images of $P$. aeruginosa biofilms are shown in Figures 3 and 4. Manuka honey exposure was associated with less extracellular matrix compared to control cells. The cells were bent and had indentations in their surfaces compared with the relatively smooth control cells. When treated with artificial honey, there was also a decrease in extracellular matrix; the cells more densely covered the disc than did the Manuka honey-exposed cells. The artificial honey appeared 


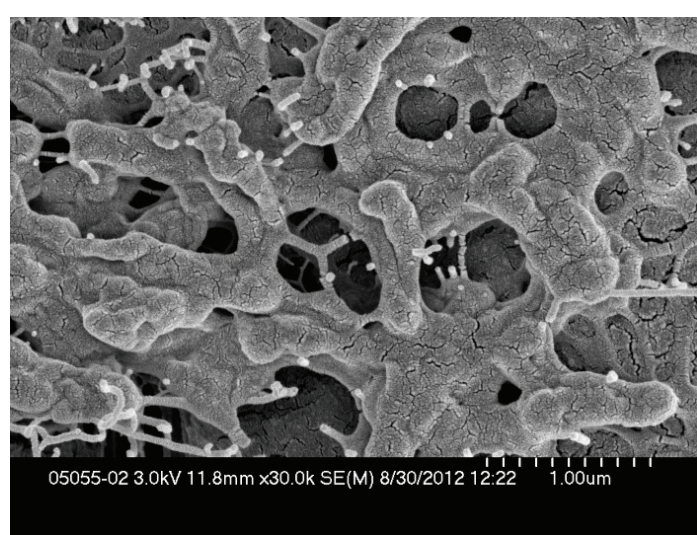

(a)

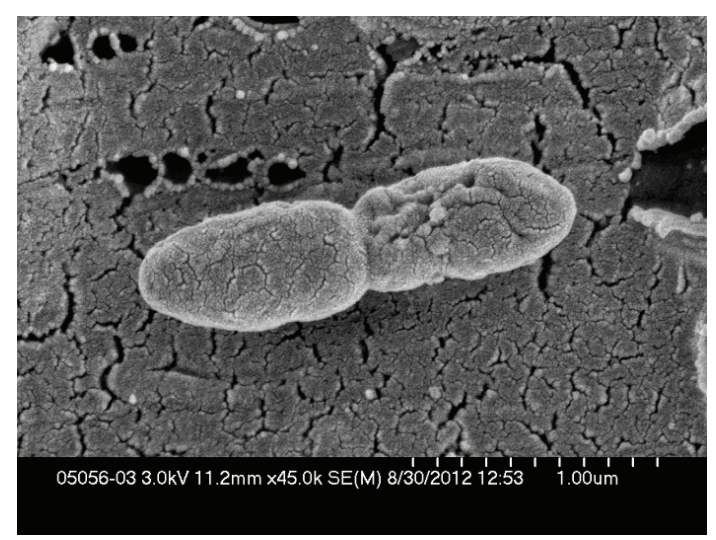

(b)

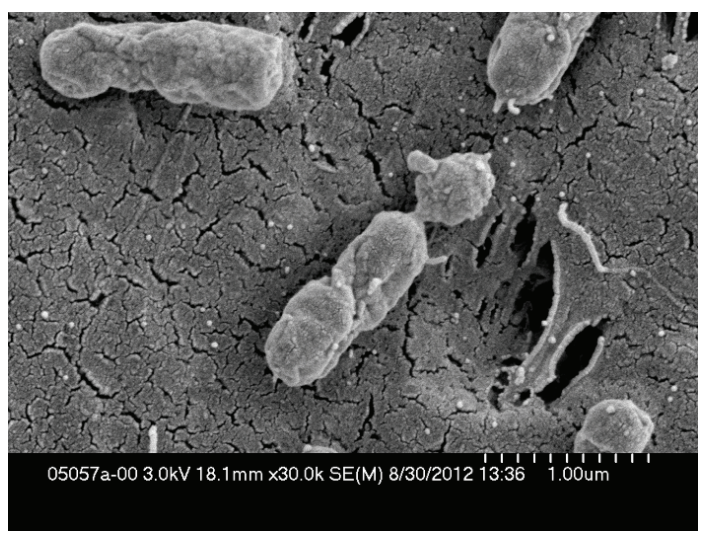

(c)

Figure 4: Scanning electron microscopy of $P$. aeruginosa biofilms (scale bar, $0.1 \mu \mathrm{m}$ )—(a) control; (b) $20 \%$ Manuka honey; (c) $50 \%$ artificial honey (representative images). In these higher magnification views, the matrix was seen only in the control images. The Manuka honeyexposed cell had multiple furrows. The Manuca honey-exposed cell appeared to be trying to divide. The artificial honey-exposed cells appeared similarly furrowed and also appeared to be trying to divide. The control biofilm was composed of many cells; the honey-exposed biofilms consisted of fewer cells.

to have more activity at the same concentration against $P$. aeruginosa than $S$. aureus biofilms, as evidenced by both the scanning electron microscopy and quantitative cultures.

Few investigators have visualized effects of Manuka honey on bacteria using electron microscopy, and to the best of our knowledge, none have done so with biofilm bacteria. Henriques et al. performed scanning electron microscopy on planktonic $P$. aeruginosa cells exposed to Manuka honey and observed loss of structural integrity and changes in cell shape, including shorter cells, distortion, and surface defects [25]. Lu et al. described both longer and shorter planktonic $P$. aeruginosa cells in response to Manuka honey exposure, depending on growth phase [2]. Jenkins et al. reported that Manuka honey-exposed planktonic $S$. aureus cells were enlarged and had more septa [26], whereas Lu et al. reported shorter planktonic cells [2].

Together, our results show that Manuka honey has visually appreciable activity against established $S$. aureus and $P$. aeruginosa biofilms, that subinhibitory Manuka honey concentrations increase vancomycin's activity against $S$. aureus biofilms, and that Manuka honey has an additive interaction with gentamicin against $P$. aeruginosa biofilms.

\section{Conclusions}

Manuka honey has in vitro antibiofilm activity. We demonstrated that subinhibitory concentrations of Manuka honey increase the killing activity of vancomycin against $S$. aureus biofilms and that Manuka honey has an additive interaction with gentamicin against $P$. aeruginosa biofilms. This interaction may be clinically useful in medical practices where topical Manuka honey might be delivered in combination with conventional antibiotics. We also used scanning electron microscopy to visualize the effect of Manuka honey on $S$. aureus and $P$. aeruginosa biofilms; distorted morphologies of both species were seen, along with a decreased amount of $P$. aeruginosa biofilm extracellular matrix.

\section{Conflict of Interests}

The authors declare that there is no conflict of interests regarding the publication of this paper.

\section{References}

[1] P. H. S. Kwakman, A. A. te Velde, L. de Boer, C. M. J. E. Vandenbroucke-Grauls, and S. A. J. Zaat, “Two major medicinal 
honeys have different mechanisms of bactericidal activity," PLoS One, vol. 6, no. 3, Article ID e17709, 2011.

[2] J. Lu, D. A. Carter, L. Turnbull et al., "The effect of New Zealand kanuka, manuka and clover honeys on bacterial growth dynamics and cellular morphology varies according to the species," PloS One, vol. 8, no. 2, Article ID e55898, 2013.

[3] C. J. Adams, C. H. Boult, B. J. Deadman et al., "Isolation by HPLC and characterisation of the bioactive fraction of New Zealand manuka (Leptospermum scoparium) honey," Carbohydrate Research, vol. 343, no. 4, pp. 651-659, 2008.

[4] E. Mavric, S. Wittmann, G. Barth, and T. Henle, "Identification and quantification of methylglyoxal as the dominant antibacterial constituent of Manuka (Leptospermum scoparium) honeys from New Zealand," Molecular Nutrition and Food Research, vol. 52, no. 4, pp. 483-489, 2008.

[5] J. Majtan, J. Klaudiny, J. Bohova et al., "Methylglyoxal-induced modifications of significant honeybee proteinous components in manuka honey: possible therapeutic implications," Fitoterapia, vol. 83, no. 4, pp. 671-677, 2012.

[6] H. K. P. English, A. R. C. Pack, and P. C. Molan, "The effects of manuka honey on plaque and gingivitis: a pilot study," Journal of the International Academy of Periodontology, vol. 6, no. 2, pp. 63-67, 2004.

[7] T. Alandejani, J. Marsan, W. Ferris, R. Slinger, and F. Chan, "Effectiveness of honey on Staphylococcus aureus and Pseudomonas aeruginosa biofilms," Otolaryngology, vol. 141, no. 1, pp. 114-118, 2009.

[8] P. Merckoll, T. Ø. Jonassen, M. E. Vad, S. L. Jeansson, and K. K. Melby, "Bacteria, biofilm and honey: a study of the effects of honey on "planktonic" and biofilm-embedded chronic wound bacteria," Scandinavian Journal of Infectious Diseases, vol. 41, no. 5, pp. 341-347, 2009.

[9] J. Jervis-Bardy, A. Foreman, S. Bray, L. Tan, and P.-J. Wormald, "Methylglyoxal-infused honey mimics the anti-Staphylococcus aureus biofilm activity of manuka honey: potential Implication in Chronic Rhinosinusitis," The Laryngoscope, vol. 121, no. 5, pp. 1104-1107, 2011.

[10] S. E. Maddocks, M. S. Lopez, R. S. Rowlands, and R. A. Cooper, "Manuka honey inhibits the development of Streptococcus pyogenes biofilms and causes reduced expression of two fibronectin binding proteins," Microbiology, vol. 158, no. 3, pp. 781-790, 2012.

[11] O. Okhiria, A. Henriques, N. Burton, A. Peters, and R. Cooper, "Honey modulates biofilms of Pseudomonas aeruginosa in a time and dose dependent manner," Journal of ApiProduct and ApiMedical Science, vol. 1, no. 2, pp. 6-10, 2009.

[12] J. Majtan, J. Bohova, M. Horniackova, J. Klaudiny, and V. Majtan, "Anti-biofilm effects of honey against wound pathogens Proteus mirabilis and Enterobacter cloacae," Phytotherapy Research, vol. 28, no. 1, pp. 69-75, 2014.

[13] S. E. Maddocks, R. E. Jenkins, R. S. Rowlands, K. J. Purdy, and R. A. Cooper, "Manuka honey inhibits adhesion and invasion of medically important wound bacteria in vitro," Future Microbiology, vol. 8, no. 12, pp. 1523-1536, 2013.

[14] A. V. Kamaratos, K. N. Tzirogiannis, S. A. Iraklianou, G. I. Panoutsopoulos, I. E. Kanellos, and A. I. Melidonis, "Manuka honey-impregnated dressings in the treatment of neuropathic diabetic foot ulcers," International Wound Journal, 2012.

[15] R. E. Jenkins and R. Cooper, "Synergy between oxacillin and manuka honey sensitizes methicillin-resistant Staphylococcus aureus to oxacillin," The Journal of Antimicrobial Chemotherapy, vol. 67, no. 6, pp. 1405-1407, 2012.
[16] R. Jenkins and R. Cooper, "Improving antibiotic activity against wound pathogens with manuka honey in vitro," PloS One, vol. 7, no. 9, Article ID e45600, 2012.

[17] R. A. Cooper, P. C. Molan, and K. G. Harding, “The sensitivity to honey of Gram-positive cocci of clinical significance isolated from wounds," Journal of Applied Microbiology, vol. 93, no. 5, pp. 857-863, 2002.

[18] K. L. Frank, E. J. Reichert, K. E. Piper, and R. Patel, "In vitro effects of antimicrobial agents on planktonic and biofilm forms of Staphylococcus lugdunensis clinical isolates," Antimicrobial Agents and Chemotherapy, vol. 51, no. 3, pp. 888-895, 2007.

[19] M. G. Botelho, "Fractional inhibitory concentration index of combinations of antibacterial agents against cariogenic organisms," Journal of Dentistry, vol. 28, no. 8, pp. 565-570, 2000.

[20] R. Jenkins, M. Wootton, R. Howe, and R. Cooper, "Susceptibility to manuka honey of Staphylococcus aureus with varying sensitivities to vancomycin," International Journal of Antimicrobial Agents, vol. 40, no. 1, pp. 88-89, 2012.

[21] V. Mullai and T. Menon, "Bactericidal activity of different types of honey against clinical and environmental isolates of Pseudomonas aeruginosa," Journal of Alternative and Complementary Medicine, vol. 13, no. 4, pp. 439-441, 2007.

[22] S. Mukherjee, S. Chaki, S. Das, S. Sen, S. K. Dutta, and S. G. Dastidar, "Distinct synergistic action of piperacillin and methylglyoxal against Pseudomonas aeruginosa," Indian Journal of Experimental Biology, vol. 49, no. 7, pp. 547-551, 2011.

[23] J. M. Packer, J. Irish, B. R. Herbert et al., "Specific non-peroxide antibacterial effect of manuka honey on the Staphylococcus aureus proteome," International Journal of Antimicrobial Agents, vol. 40, no. 1, pp. 43-50, 2012.

[24] R. A. Cooper, L. Jenkins, A. F. M. Henriques, R. S. Duggan, and N. F. Burton, "Absence of bacterial resistance to medical-grade manuka honey," European Journal of Clinical Microbiology and Infectious Diseases, vol. 29, no. 10, pp. 1237-1241, 2010.

[25] A. F. Henriques, R. E. Jenkins, N. F. Burton, and R. A. Cooper, "The effect of manuka honey on the structure of Pseudomonas aeruginosa," European Journal of Clinical Microbiology and Infectious Diseases, vol. 30, no. 2, pp. 167-171, 2011.

[26] R. Jenkins, N. Burton, and R. Cooper, "Manuka honey inhibits cell division in methicillin-resistant Staphylococcus aureus," Journal of Antimicrobial Chemotherapy, vol. 66, no. 11, Article ID dkr340, pp. 2536-2542, 2011. 

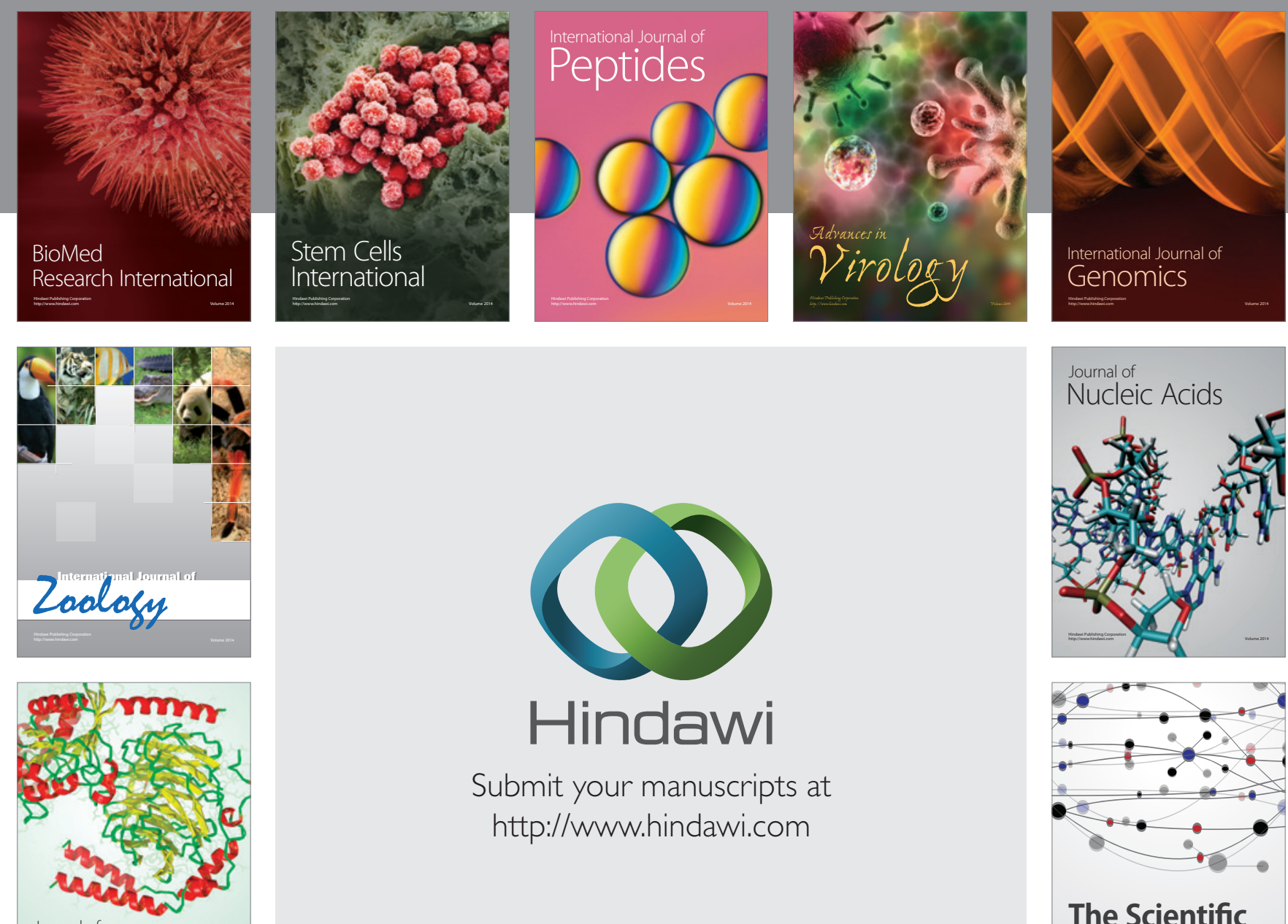

Submit your manuscripts at

http://www.hindawi.com

Journal of
Signal Transduction
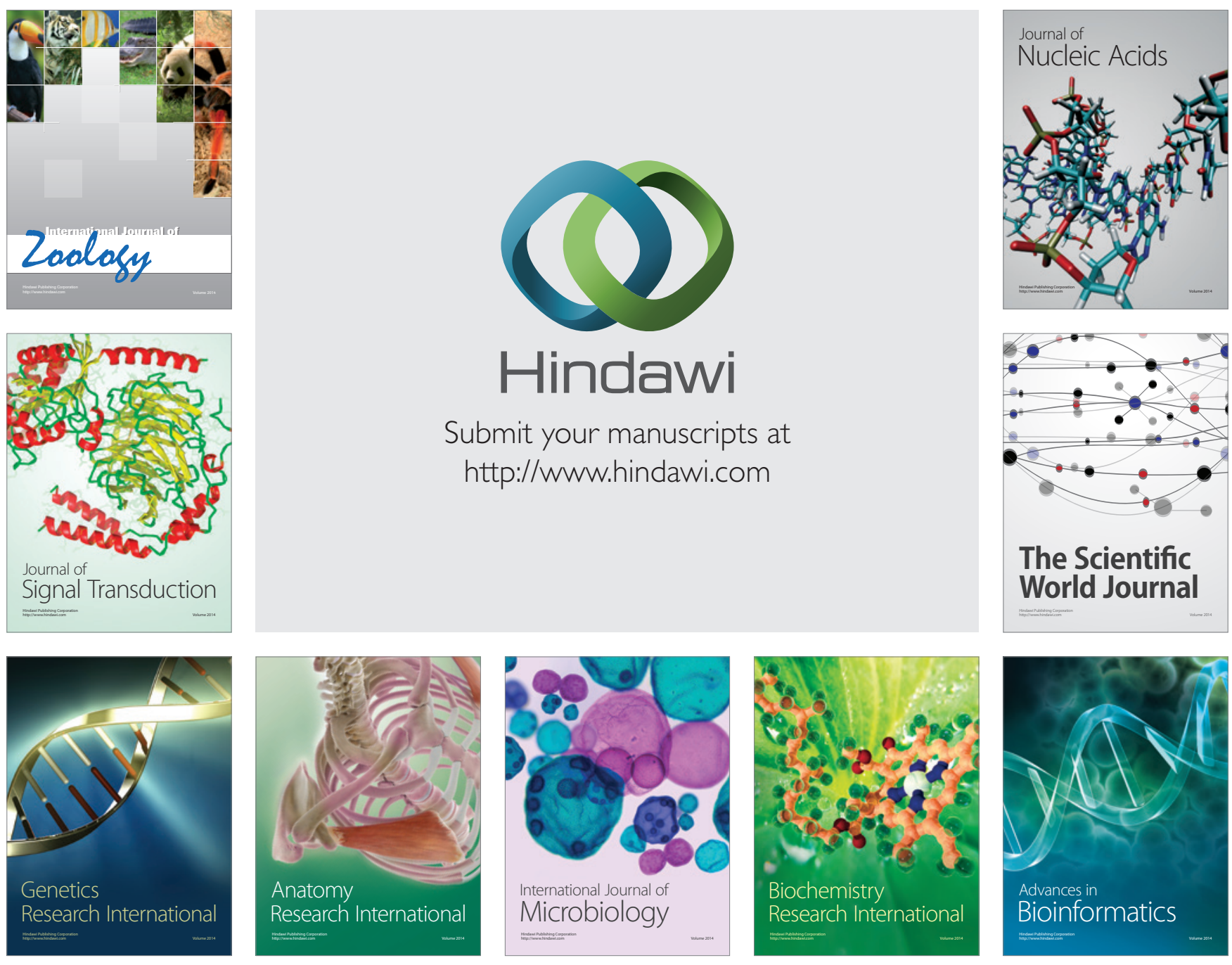

The Scientific World Journal
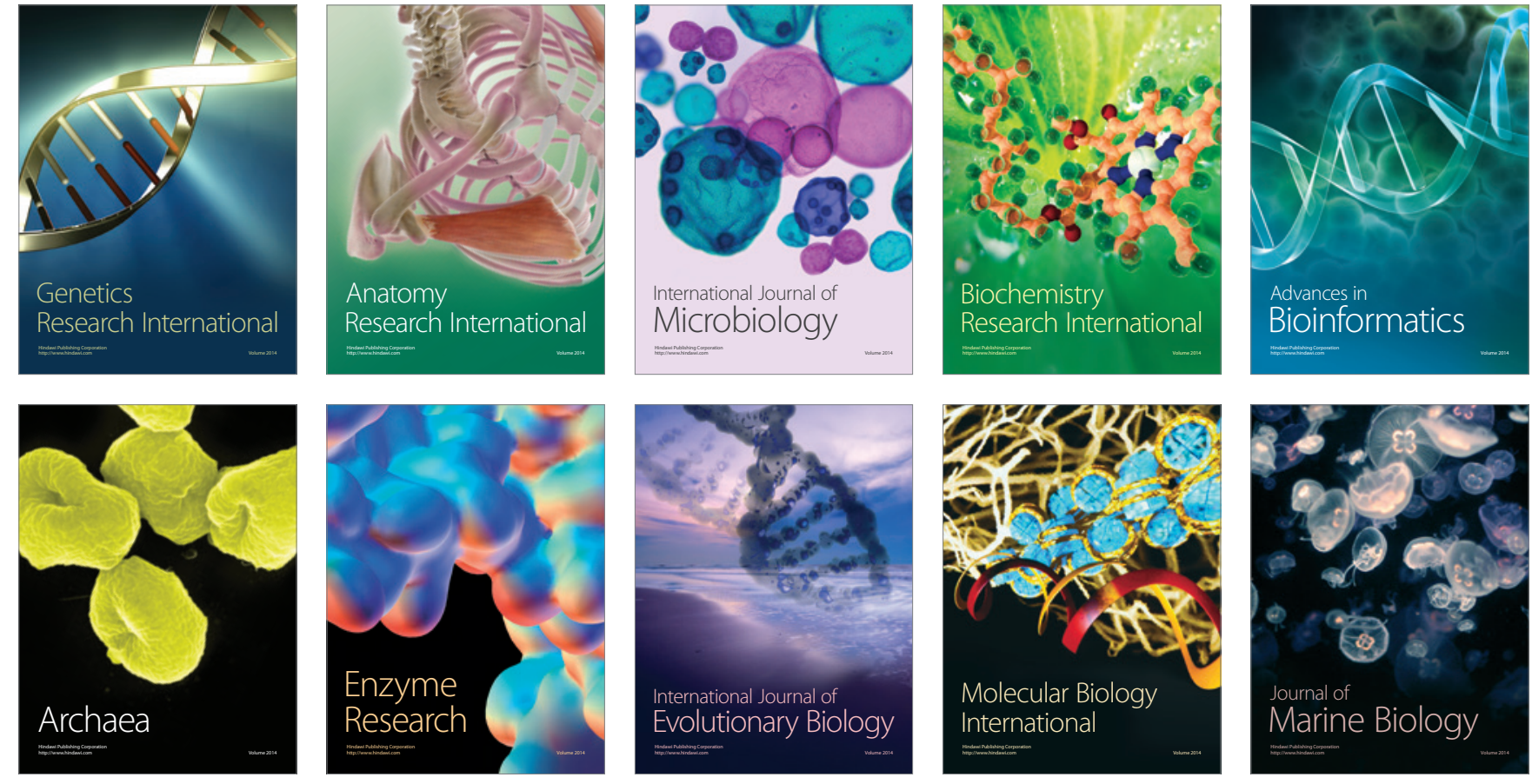